\title{
Gender Differences in Motivation and Teacher Performance in Core Functions in Kenyan Secondary Schools
}

\author{
Catherine K. Wanakacha \\ Faculty of Education, \\ Catholic University of Eastern Africa, \\ Kisumu campus-Kenya \\ Dr Peter J O Aloka \\ Jaramogi Oginga Odinga University of Science \& Technology, \\ Psychology \& Educational Foundations, Bondo-Kenya \\ Mr Philip Nyaswa \\ Catholic University of Eastern Africa, \\ Kisumu campus-Kenya
}

Doi: 10.2478/ajis-2018-0009

\begin{abstract}
This study investigated gender differences in teacher motivation and performance of the core functions. A mixed method research approach was adopted and within it the concurrent triangulation design was used. The target population was 223 teachers, 45 Principals, 45 DOS's, and 1 DQASO. The sample size comprised of 100 teachers, 14 Principals, 14 HOD's Co-curricular, 14 DOS's and 1 DQASO. Validity was ensured by expert judgment by University supervisors at CUEA and their input were incorporated in the final document while reliability of the instruments was ensured and determined by piloting the instruments in four secondary schools of different categories which constituted $10 \%$ of the population. A Cronbach reliability coefficient of 0.7134 was reported. Data collected from questionnaire was analyzed using descriptive statistics in form of percentages, means and frequency counts as well as independent samples t-test. The study reported that gender difference did not have an effect on both intrinsic and extrinsic motivation of teachers to perform their core functions. The study also found that gender difference did not have an effect on teachers to perform their core functions. The Kenyan Teachers Service Commission should work out incentive packages to increase teachers' motivation to perform their core functions effectively.
\end{abstract}

Keywords: Gender Differences; Motivation; Teacher Performance; Core Functions; Kenya; Secondary Schools

\section{Introduction}

Teachers' job performance is a societal concern. This is because the teachers play a critical role in shaping the lives of learners as they perform various core functions assigned; they interact with the learners more regularly than the learners interact with their parents. With reference to an article by OSBA in 2009 on Motivating teachers to improve instruction, the history of Teacher Motivation Measures are traced in the last three decades of education reform where teachers had been viewed as central to both the problems of education and their solutions. Education researchers and school leaders faced the challenge of motivating teachers to high levels of performance. In the 
1980's, state governments in the United States of America (USA) and its local school districts enacted an array of incentives plans designed to recruit, reward and retain the best teachers. Merit pay and career ladders were intended to provide financial incentives, varied work, and advancement opportunities for seasonal teachers. These, along with across-the-board pay rises, work environment, premiums for difficult assignment, and grants or sabbaticals for research and study, were expected to improve teacher performance and motivation. However, according to Johnson (1986), merit pay could change the relationship between teachers and students.

Frase (1992) offered one reason why measures relying on external rewards had been insufficient. There was overwhelming research evidence he said, that teachers who entered teaching to help people to learn, that their most gratifying reward was accomplishing goals, and that the work related factors most important to teachers, were those that allowed them to practice their craft successfully. Frase (1992) identified two sets of factors that affected teachers' ability to perform effectively: work context factors and work content factors. Later, Monahan (1996) described a new concept, Comprehensive Professional Development (CPD) that focused on strategies for facilitating teacher growth through professional dialogue with colleagues, collaborative curriculum development, peer supervision, peer coaching, and action research leading to school wide change. Unfortunately, he reported, Principals and teachers still regarded CPD like activities for continuing professional development to be less important than traditional methods. Therefore, having looked at teacher motivation for the past years, many researchers have proved that teacher motivation depends on their beliefs towards the motivating factors, their knowledge, assumptions and attitudes they hold about their work (Naseer Ud Din, Tufail, Shereen, Nawaz and Shahbaz, 2012). The field of education presently acknowledges that teacher motivation contributes to the understanding of the dynamism in the teaching and learning processes. Accordingly, past studies have confirmed that teachers who are not motivated may experience chronic drop in performance that over long period may lead to teacher burn-out. In this regard, teachers who have been victims of de-motivation may develop emotional exhaustion, low personal accomplishment, and depersonalization (Skaalvik and Skaalvik, 2009).

A significant percentage of secondary school leavers in Kenya were employed first as teachers before joining college and other institutions of professional studies. The corresponding figures for Siaya Sub-County were staggering at $41 \%$ (Yewah, 2015). Consequently, teachers often lacked a strong, long term commitment to teaching as a vocation (Yewah, 2015).In Kenya, the Ministry of Education, Science and Technology (MOEST) controls all the levels of education through various bodies such as Kenya National Examinations Council (KNEC), Kenya Institute of Curriculum Development (KICD) and Kenya Education of Management Institute (KEMI). MOEST establishes schools and carries out assessment to ensure that teachers are offering quality services as they perform their respective core functions. It also provides all the recommended and relevant teaching and learning materials to schools by remitting funds for Free Day Secondary Education (FDSE) under which allocation is made for the instructional materials. KICD develops, prescribes and reviews the national curriculum. It approves all text books and teaching and learning materials required in schools in the orange book. TSC is an autonomous body in the current constitution of Kenya (2010). According to the TSC Act (No.20 of 2012), the commission has been assigned many functions. It registers, recruits and employs registered teachers, promotes, transfers and disciplines teachers in the entire country. Finally, KEMI trains teachers and organizes capacity building for administrators to ensure they are developed professionally to offer quality services and maintain professionalism (Aseka, 2016).

This study was based on Expectancy -value theory. Expectancy theory was founded by Martin Fishbein in 1970's. Expectancy theory refers to a set of decision theories of work, motivation and performance (Yung Chou \& Pearson, 2012).According to the theory, behavior is a function of expectancies one has and the value of the goal toward which one is working. Perception plays a pivotal role in expectancy theory because it emphasizes cognitive ability to anticipate likely consequences of behavior. Underlying expectancy-value theory is the belief that humans are innately active learners with an inborn curiosity and an urge to get to know their environment and meet challenges, and therefore the main issue in this value theory is not what motivates teachers but rather what directs and shapes their inherent motivation. Using data from approximately 9,000 
faculty members that participated in the Faculty Survey of Student Engagement, Laird (2007) asserted that gender differences in the percentage of class time spent on various activities, a measure of class teaching style, and the lecturing practice were signs of the gaps between male and female teachers in terms of performance in core functions. Research by Anderson (2011) tried to find out whether gender of teachers influenced their self-efficacy and job satisfaction in Denmark.

The researcher found out those female teachers in Danish schools had higher level of job satisfaction and self-efficacy than their male counterparts, and that female teachers had higher level of empathy.

Muralidharan (2016) studied gender gaps in learning outcomes and the effectiveness of the gender of teachers in reducing inequality in learning. The author found out that female teachers were more effective in teaching students of their own gender. The author also asserted that while there was no effect on same gender teacher on student attendance, girls were more likely to perform better when they were taught by female teachers, and the teachers were also likely to perform well in core functions. Ogheneakoke (2015) tried to assess teachers' competencies in the use of inquiry method within secondary schools in Nigeria. The findings showed that there was no significant distinction between male and female social studies teachers' competences in the use of inquiry method in upper basic schools. In a study to determine the influence of gender on staff productivity in selected private universities in Kampala, Uganda, Anumaka and Ssemugenyi (2013) used null hypothesis of no significant difference regarding performance in core functions between male and female employees was tested. The findings showed that productivity did not differ significantly among employees apart from the punctuality aspect of work which was relatively higher in men. Based on a rich dataset that was made up of 1,800 primary schools and 40,000 students in ten francophone Sub-Saharan African countries, Lee, Rhee and Rudolf (2017) found out the link between teacher gender, student gender, and performance level. The results indicated that female teachers had high level of achievement in terms of teaching style, and this had considerable influence on female and male students' achievement. Matheri (2015) determined the effects of principals' gender on leadership effectiveness in secondary schools in Mtito-Andei, Kibwezi SubCounty, Kenya. Results indicated that there was no significant relationship between the gender of principals and the effectiveness in the management of discipline and personnel in the schools environment. In a study by Waseka, Simatwa and Okwach (2016) to assess the influence of teacher factors on the performance of learners in secondary schools in Kakamega, the study found out that gender difference between male and female teachers was statistically significant determinants of students' academic performance. The study revealed that female teachers had the capacity to perform in core functions than male teachers since majority of students preferred being taught by female teachers.

In Siaya Sub-County a report of 2015 by the County Education Office revealed that teachers were devoting less and less time to co-curricular activities, teaching preparation, and marking. In addition, deteriorating standards of professional conduct, including serious misbehavior (in and outside of work), and poor professional performance had been observed in some secondary schools within Siaya Sub- County. These were indications of lack of motivation among teachers, thereby affecting performance in core functions (Anusu, Barasa \& Omulando, 2014). In light of the above situation, the present study which examined the relationship between motivation and teachers' performance of core functions was necessary within Siaya Sub-County of Kenya.

\section{Research Methodology}

A mixed method research approach was adopted and within it the concurrent triangulation design was used. The target population was 223 teachers, 45 Principals, 45 DOS's, and1DQASO.The sample size comprised of 100 teachers, 14 Principals, 14 HOD's Co-curricular, 14 DOS's and 1 DQASO. Validity was ensured by expert judgment by University supervisors at CUEA and their input were incorporated in the final document while reliability of the instruments was ensured and determined by piloting the instruments in four secondary schools of different categories which constituted $10 \%$ of the population. A Cronbach reliability coefficient of 0.7134 was reported. Data collected from questionnaire was analyzed using descriptive statistics in form of percentages, 
means and frequency counts as well as inferential statistics such as Independent sample T-test. Qualitative data from interviews and open-ended questions were organized into categories and sub-categories while data obtained from document analysis was analyzed using content analysis.

\section{Findings and Discussion}

It was investigated by use of independent-samples t-test analysis. First, the study sought to establish gender differences in intrinsic motivation among secondary school teachers, gender differences in extrinsic motivation among secondary school teachers and gender differences in motivation and teacher performance in core functions. Results were as computed in subsequent tables. an independent-samples t-test was conducted to compare intrinsic motivation with respect to their gender difference. Table1 shows the response:

Table 1: Independent samples T-Test output for intrinsic motivation among teachers

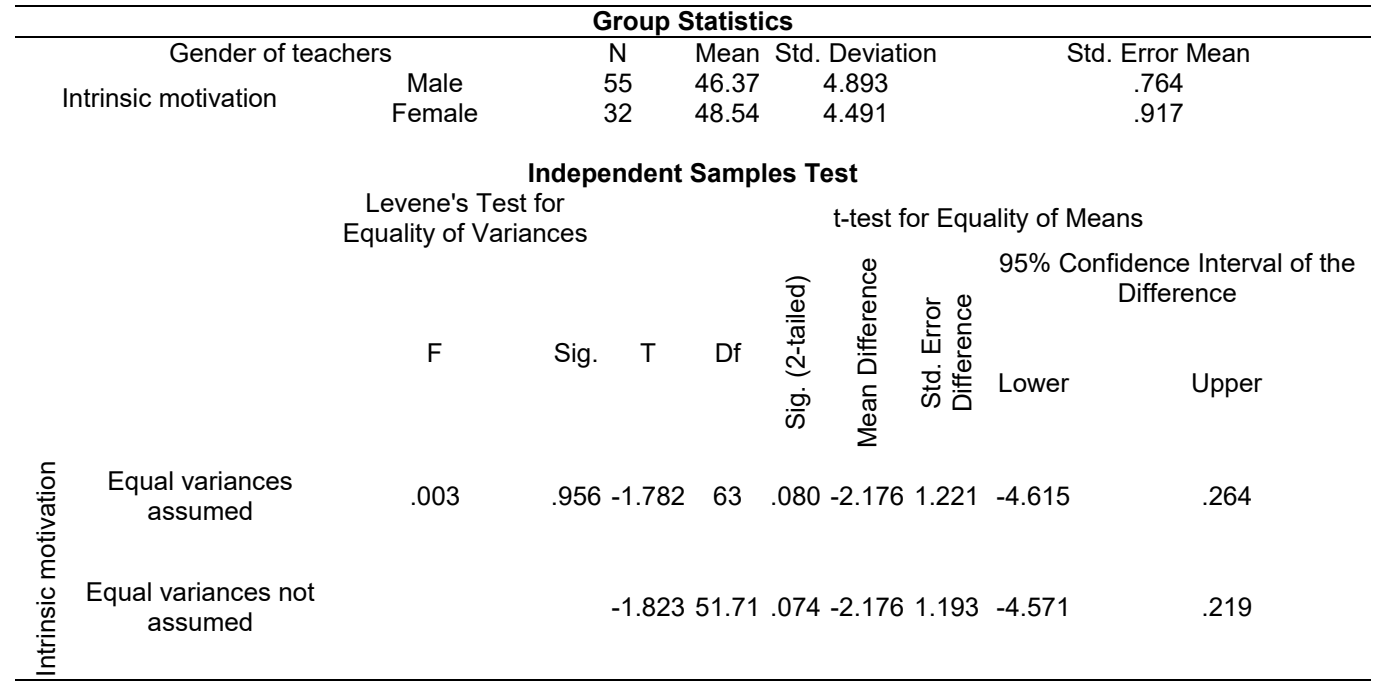

There was no significant difference in the scores for male $(M=46.37, S D=4.89)$ and female $(M=48.54, S D=4.491)$ gender; $t(63)=-1.782, P=0.08$. These results suggest that gender difference does not have an effect on intrinsic motivation of teachers to perform their core functions. Specifically, our results suggest that irrespective of the gender difference, intrinsic motivation of teachers influence their performance in core functions. Similarly, in a study to determine the influence of gender on staff productivity in selected private universities in Kampala, Uganda, Anumaka and Ssemugenyi (2013) used null hypothesis of no significant difference. The findings showed that productivity does not differ significantly among employees apart from the punctuality aspect of work which was relatively higher in men. However, Kati, Owiti, and Ongati's (2013) findings revealed a significant correlation between the gender of the teacher and learners' achievement in primary Mathematics.

An independent-samples t-test was conducted to compare extrinsic motivation with respect to their gender difference. Table 2 shows the response:

Table 2: Independent samples T-Test output for extrinsic motivation among teachers

\begin{tabular}{|c|c|c|c|c|c|}
\hline \multicolumn{6}{|c|}{ Group Statistics } \\
\hline \multicolumn{2}{|c|}{ Gender of teachers } & $\mathrm{N}$ & Mean & Std. Deviation & Std. Error Mean \\
\hline & Male & 55 & 39.05 & 5.366 & .838 \\
\hline Extrinsic motivation & Female & 32 & 39.04 & 5.377 & 1.098 \\
\hline & & & 92 & & \\
\hline
\end{tabular}




\begin{tabular}{|c|c|c|c|c|c|c|c|c|c|c|}
\hline & & & & ende & Sample & est & & & & \\
\hline & & Levene & Test $\mathrm{fc}$ & & & & & & & \\
\hline & & Equ & $y$ of & & & t-test & r Equa & of Mea & & \\
\hline & & $F$ & Sig. & $\mathrm{T}$ & $\mathrm{df}$ & 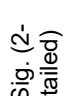 & 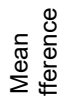 & 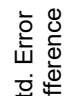 & $\begin{array}{r}95 \% \text { C } \\
\text { Interv } \\
\text { Diff }\end{array}$ & $\begin{array}{l}\text { dence } \\
\text { f the } \\
\text { hce }\end{array}$ \\
\hline & & & & & & & 次 & & Lower & Upper \\
\hline & $\begin{array}{l}\text { Equal variances } \\
\text { assumed }\end{array}$ & .262 & .610 & .005 & 63 & .996 & .007 & 1.380 & -2.751 & 2.765 \\
\hline 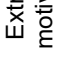 & $\begin{array}{c}\text { Equal variances not } \\
\text { assumed }\end{array}$ & & & .005 & 48.22 & .996 & .007 & 1.381 & -2.769 & 2.783 \\
\hline
\end{tabular}

There was no significant difference in the scores for male $(M=39.05, S D=5.37)$ and female $(M=39.04, S D=5.377)$ gender; $t(63)=0.005, P=0.996$. These results suggest that gender difference does not have an effect on extrinsic motivation of teachers to perform their core functions. Specifically, our results suggest that irrespective of the gender difference, extrinsic motivation of teachers influence their performance in core functions. These findings agrees with that of Ogheneakoke (2015) who also found that there was no significant distinction between male and female social studies teachers' competences in the use of inquiry method in upper basic schools. The author argued that the male and female social studies teachers demonstrated the same level of competence. However, Lee, Rhee and Rudolf (2017) contradicted these findings when they found out the link between teacher gender, student gender, and performance level. The results indicated that female teachers had high level of achievement in terms of teaching style, and this had considerable influence on female and male students' achievement.

The Hypothesis Testing on Gender Difference in Secondary School's Teacher Performance in Core Functions was as follows:

$\mathrm{Ho}_{1}$ : There are no significant gender differences in teacher performance in core functions in secondary schools in Siaya Sub-County.

An independent-samples t-test was conducted to compare performance of teachers in core functions with respect to gender. Table 3 shows the response.

Table 3: Independent samples T-Test output for performance of core functions among teachers

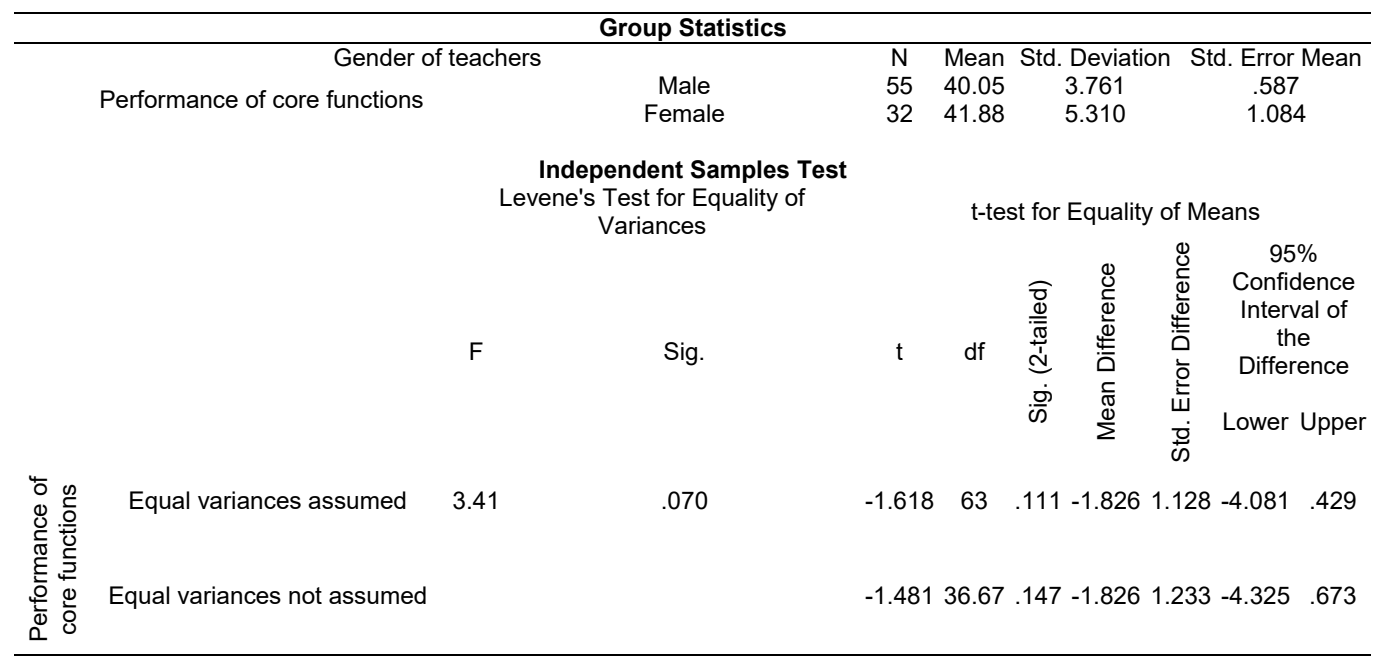

There was no significant difference in the scores for male $(M=40.05, S D=3.76)$ and female 
$(M=41.88, S D=5.31)$ gender; $t(63)=-1.618, P=0.111$. Since the $P$-value obtained was 0.111 and it was greater than 0.05 then the null hypothesis which stated that, "There are no significant gender differences in teacher performance in core functions in secondary schools in Siaya Sub-County", was accepted. These results suggest that gender difference does not have an effect on teachers to perform their core functions. Specifically, our results suggest that irrespective of the gender difference, teachers' performance in core functions may vary. However, these findings contradicts that of Research by Anderson (2011) who then found that female teachers in Danish schools had higher level of job satisfaction and self-efficacy than their male counterparts, and that female teachers had higher level of empathy.

Qualitative data on gender differences in performance in core functions indicated that in most cases, there were differences. Some participants reported that:

\begin{abstract}
"Male teachers perform slightly higher than female teachers since most men are active in terms of arrival in school, performing duties such as in games that very few female teachers can do" (HOD, 4)

"Male teachers perform higher than females. The female teachers are not aggressive in school and are not able to do many things like the males teachers do" (Principal, 2)

"Male teachers are risk takers even in a working environment unlike the female teachers who are unwilling to go an extra mile for the sake of students" (Principal, 4)
\end{abstract}

From the excerpts above, it can be concluded that there was gender differences in teacher performance in core functions. This finding agrees with Laird (2007) who asserts that gender differences in the percentage of class time spent on various activities, a measure of class teaching style, and the lecturing practice are signs of the gaps between male and female teachers in terms of performance in core functions. Similarly, Anderson (2011) found out that female teachers in Danish schools have higher level of job satisfaction and self-efficacy than their male counterparts, and that female teachers have higher level of empathy. In addition, Ogheneakoke (2015) reported that there is no significant distinction between male and female social studies teachers' competences in the use of inquiry method in upper basic schools. Moreover, Anumaka and Ssemugenyi (2013) reported that productivity does not differ significantly among employees apart from the punctuality aspect of work which was relatively higher in men.

\title{
4. Conclusion and Recommendation
}

Based on an independent-samples t-test, the study concluded that there was no significant difference in the scores for male $(M=46.37, S D=4.89)$ and female $(M=48.54, S D=4.491)$ gender; $t$ (63) $=-1.782, P=0.08$. In conclusion, gender difference does not have an effect on intrinsic motivation of teachers to perform their core functions. Specifically, irrespective of the gender difference, intrinsic motivation of teachers influences their performance in core functions. Similarly, on whether there was gender difference in extrinsic motivation among secondary school teachers, an independent-samples t-test shows that there was no significant difference in the scores for male $(M=39.05, S D=5.37)$ and female $(M=39.04, S D=5.377)$ gender; $t(63)=0.005, P=0.996$. The study therefore concluded that gender difference does not have an effect on extrinsic motivation of teachers to perform their core functions. Specifically, irrespective of the gender difference, extrinsic motivation of teachers influences their performance in core functions. Finally, on whether there was gender difference in performance of core functions among secondary school teachers, an independent-samples t-test results shows that there was no significant difference in the scores for male $(M=40.05, S D=3.76)$ and female $(M=41.88, S D=5.31)$ gender; $t(63)=-1.618, P=0.111$. In conclusion, gender difference does not have an effect on teachers to perform their core functions. Specifically, irrespective of the gender difference, teachers' performance in core functions may vary. The School Board of Management should develop appropriate and achievable motivation strategies for the teachers in their schools. This is because the study reported that both intrinsic and extrinsic motivation enhanced teacher performance in their core functions. 


\section{References}

Anderson, L.B. (2011). Teacher Diversity: Do Male and Female Teachers have Different Self-Efficacy and Job Satisfaction? Department of Political Science, Aarhus University \& Danish Institute of Governmental. Research Paper Prepared for the 33rd EGPA Conference in Bucharest7-10. September 2011.

Anusu O.M., P. L. Barasa, \& Omulando C.A (2014).Challenges Teachers Face in the Use of the Communicative Language Teaching Approach in the Teaching Listening and Speaking Lessons in Lugari District, Kenya. Creative commons International Journal of Science and Research.Vol.3 (9), pp.83-92.

Anumaka, I. B., \& Ssemugenyi, F. (2013).Gender and Work-Productivity of Academic Staff in Selected Private Universities in Kampala City, Uganda. International Journal of Research in Business Management, 1(3), 29-36.

Aseka, M.T (2016).Influence of Head teachers' Instructional Supervision Practices on Teachers' Job Performance in Public Primary Schools in Lang'ata Sub-County. Nairobi, Kenya. (Doctoral dissertation, University of Nairobi).

Johnson, S.M (1986). Incentives for Teachers: What Motivates, What Matters? Educational Administration Quarterly Vol.22, No. 3(Summer 1986):54-79.

Frase, L.E (1992).Maximizing People's Power in Schools: Motivating and Managing Teachers and Staff. Newsbury Park, CA: Corwin Press, Inc.

Lee, J., Rhee, D. E., \& Rudolf, R. (2017).Teacher Gender, Student Gender, and Primary School Achievement: Evidence from Ten Francophone African Countries. Graduate School of International studies, Korea University.

Matheri, E. W. (2015). Effects of Principals' Gender on Leadership Effectiveness in Secondary Schools in MtitoAndei Division, Kibwezi Sub-County, Kenya. Journal of Education Practice, V6 n14 pp 12-17

Muralidharan, K. (2016). Bridging Education Gender Gaps in Developing Countries: The Role of Female Teachers. UC San Diego, NBER, BREAD, J-PAL.

Naseer Ud Din, M., Tufail, H., Shereen, S., Nawaz, A., \& Shahbaz, A. (2012).Factors Affecting Teacher Motivation at Secondary School Level in Kohat City. Inter-Disciplinary Journal of Contemporary Research in Business, 3 (10), pp 442-449.

Ogheneakoke, C. (2015). Gender Difference among Social Studies Teachers' Competences in the Use of the Inquiry Method in South-South Nigeria. Journal of Education and Practice, 6(23), 48-51.

Skaalvik, E. M., \& Skaalvik, S. (2014). Teacher Self-Efficacy and Perceived Autonomy: Relations with Teacher Engagement, Job Satisfaction, and Emotional Exhaustion. Psychological Reports, 114(1), 68-77.

Yewah, C.O. (2015). Institutional Factors Influencing Quality Training in Technical, Vocational and Entrepreneurship Training in Siaya Sub-County. Region, Kenya. (Doctoral Dissertation, University of Nairobi).

Yung Chou, S., \& Pearson, J.M.(2012).Organizational citizenship behavior in IT professionals: An expectancy theory approach. Management Research Review, 35(12), -1186).

Laird, N. (2007).Gender Gaps: Understanding Teaching Style Differences between Men and Women, A Paper Presented at the Annual Meeting of the Association for Institutional Research.

Waseka, E.L, M.W. Simatwa \& Okwach, T. (2016).Influence of Teacher Factors on Students' Academic Performance in Secondary School Education. A Case Study of Kakamega County, Kenya. Department of Educational Management and Foundations, Maseno University. Department of Educational Communication, Technology and Curriculum studies, Maseno University, Greener Journal of Educational Research. Research Paper. DOI:http://doi.org/10.15580/GJER.2016.4.060216102). 